\title{
HEALTH CARE EXPENDITURES IN OECD COUNTRIES: A PANEL UNIT ROOT AND COINTEGRATION ANALYSIS DREGER, Christian", REIMERS, Hans-Eggert
}

\section{Abstract:}

This paper examines the link between health care expenditures and GDP for 21 OECD countries using panel cointegration techniques. The analysis accounts for the fact that health care expenditures are not solely driven by income, but also by medical progress, where different measures are used. In the extended models, cointegration can be established. The income elasticity is not different from unity, implying that health care is not a luxury good. This finding is robust for alternative proxies of medical progress, and various estimators of the cointegration vector. In addition, cointegration can be detected even between nonstationary common factors.

Key words: Health care expenditures; medical progress, panel cointegration, common factors

JEL classification: C23, I10

\section{Introduction}

Since the work of Newhouse (1977) it has been widely debated, whether health care expenditures are a luxury good. Much of the early research on this topic have detected an income elasticity larger than unity, mplying that the share of health expenditures in GDP will increase with per capita income, see for example OECD (1985). Other authors, like Hitiris and Posnett (1992) reported an income elastictity of about 1, thus questionning the luxury property. However, these studies suffer from the fact that they did not control for the nonstationarity of the variables. If the stationarity assumption is

Christian Dreger, Institute for Economic Research Halle, Ge rmany, e mail: cdr@iwh-halle.de and Hans-Eggert Reimers, Hochschule Wismar, University of Technology, Business and Design, Wismar, Germany, e-mail: h.reimers@wi.hs-wismar.de 
violated, statistical evidence based on OLS regressions turns out to be spurious. After detecting unit roots in health care expenditures and GDP, Hansen and King (1996) and Blomqvist and Carter (1997) were not able to find cointegration in general, as a long run relationship seemed to exist only for a few countries.

In a panel setting, McCoskey and Selden (1998) rejected the null of nonstationarity for health care expenditures and GDP, implying that the former OLS result could be reinforced. But, they did not account for a time trend in their tests, which are based on the IPS approach, see Im, Pesaran and Shin (2003). Allowing for linear trends, Gerdtham and Löthgren $(2000,2002)$ did not reject the null of a unit root for health care expenditures and GDP in a panel of OECD countries.

They also presented evidence in favour of cointegration, but missed to report the income coefficient. Using the Engle-Granger two step strategy, Okunade and Karakus (2001) found an income elasticity larger than unity. But, Jewell, Lee, Tieslau and Strazizich (2003) questionned these results, as they seem to be affected by structural breaks. Bac and Le Pen (2002) detected cointegration in a OECD panel over the 1972-1995 period, but the cointegration vector differs substantially with the econometric technique employed. It should be noted that the panel studies available neither control for other variables entering the long run relationship between health care expenditures and GDP nor for cross section dependencies. In fact, cross section cointegration can bias the results of the panel unit roots and cointegration tests to a large extent, see Banerjee, Marcellino and Osbat (2001) and Urbain (2004).

This paper makes progress in several respects. First, we extend the sample to cover the recent period. Second, we account for the fact that health care expenditures are not only driven by income, but also by medical progress. The latter is proxied by alternative measures to foster the robustness of the results. Due to data availability, life expectancy and infant mortality are used. Medical advances are expected to lead to a rise of life expectancy and a fall in infant mortality. Third, the empirical methods applied are more comprehensive. Recent developments in the field of panel cointegration are taken 
into account, including efficient estimation techniques and common nonstationary factors.

One main finding of the paper is a cointegration relationship among health care expenditures, GDP, both real and in per capita levels, and medical progress, independently of the concrete measurement of the latter variable. Secondly, the income elasticity is not different from unity in the panel models, implying that health care expenditures are not a luxury. These findings are robust for alternative estimation techniques of the cointegration vector. As cointegration appears to hold also among the nonstationary common factors of the variables involved, long run cross section dependencies do not alter the main results.

The paper is organized as follows. In section 2, the economic relationship between health expenditures and its determinants is discussed. As we control for the role of medical progress, both health demand and supply arguments are considered. The empirical framework is outlined in section 3 . We review panel unit root and cointegration tests and efficient estimation strategies of the cointegration vector. Data issues 0and empirical results are reported in section 4. Section 5 concludes.

\section{Specification of health expenditures}

Specifications of health care expenditures are largely ad hoc (Roberts 1999). The standard analysis is carried out along the lines of a demand side framework. Thus, households resources and relative prices are the driving forces. Higher income has a positive impact on health demand. If health care is not a Giffen good, health prices enter with a negative sign. However, one main characteristic of the industrial economies is the growing share of health care expenditures in GDP. If stationarity of the relative price is assumed, the increase cannot be explained in these models. ${ }^{1}$

\footnotetext{
${ }^{1}$ For countries with data available, health prices have usually risen by more than GDP prices. The relative health price has increased over time, implying that a rising share of health expenditures is even harder to explain.
} 
For this reason, supply side variables should be considered as well. For example, medical progress might be behind the evolution. To control for its effects, Sauerland (2002) has included a linear time trend in his equation. In this paper, more sounded measures are preferred. As data on medical technologies are incomplete, proxies have to be employed. In particular, life expectancy and infant mortality are supposed to be affected by medical progress (see Lichtenberg, 2004, Okunade 2004). Life expectancy will rise in response to medical advancements, while infant mortality is going to fall. In the analysis presented below, real health expenditures per capita $H$ are modelled conditioned on real income per capita $Y$ and a distinguished measure of medical progress $T$,

$$
H_{t}=\alpha_{0}+\alpha_{1} Y_{t}+\alpha_{2} T_{t}
$$

where $t$ denotes time and the variables usually enter in logs. Due to alternative measures of medical progress, two different models are obtained, and the robustness of the results can be inferred. The income coefficient is larger than unity, if health expenditures are a luxury good.

\section{Panel unit root and cointegration tests}

The integration and cointegration properties of the variables involved determine the specification of health expenditures. If the series are integrated, equation (1) should be viewed as a long run relationship. Otherwise, a short run interpretation is appropriate. It has been widely acknowledged that standard unit root and cointegration tests can have low power against stationary alternatives for the important cases, see for example Campbell and Perron (1991). As an alternative, recently developed panel unit root and cointegration tests are applied. Since the time series dimension is enhanced by the cross section, the results rely on a broader information set. Thus, gains in power are expected, and more reliable evidence can be obtained. Furthermore, many of the time series tests have limiting distributions, which are complicated functionals of Wiener processes. In contrast, panel tests lead to statistics with Gaussian distribution in the 
limit. On the other hand, new problems are introduced. In particular, cross section cointegration may bias the panel tests, see Banerjee, Marcellino and Osbat (2001).

Here, the LLC (Levin, Lin and Chu, 2002), the IPS (Im, Pesaran and Shin, 2003) and the HD (Hadri, 2000) tests are considered. Deterministic and dynamic effects in the data generating process might differ across the panel members. The first two procedures are generalizations of the ADF principle. The null of a unit root is investigated against the alternative of a stationary process for all (LLC) or at least for one cross section (IPS). The hypotheses are interchanged by the HD procedure, which adapts the KPSS test to panels. For the LLC and IPS test, the optimal lag length is selected using the general-tosimple procedure proposed by Campbell and Perron (1991). The consistent estimator of the long run residual variance relevant for the LLC and HD statistics is obtained using the Bartlett kernel and the automatic bandwidth parameter suggested by Newey and West (1994). Provided that the degree of cross section correlation is not substantial, the statistics

$$
Z_{t}=\frac{Z_{t}^{*}-\mu}{\sigma}
$$

are asymptotically distributed as standard normal with a left (LLC, IPS) or right (HD) hand side rejection area. Standardization factors are obtained by simulation and depend on the deterministic components included in the testing procedure.

For panel cointegration, the tests suggested by Pedroni (1999) are employed. They extend the Engle and Granger (1987) two step strategy to panels and rely on ADF and PP principles. First, the cointegration equation is estimated separately for each panel member. Second, the residuals are examined with respect to the unit root feature. If the null of is rejected, the long run equilibrium exists, but the cointegration vector may be different for each cross section. In addition, deterministic components are allowed to be individual specific. The residuals are pooled either along the within or the between dimension of the panel, giving rise to the panel and group mean statistics (see Pedroni, 1999). In the case of the panel statistics the first order auto- 
regressive parameter is restricted to be the same for all cross sections. If the null is rejected, the parameter is smaller than 1 in absolute value, and the variables in question are cointegrated for all panel members. In the group statistics, the autoregressive parameter is allowed to vary over the cross section, as the statistics amount to the average of individual statistics. If the null is rejected, cointegration holds at least for one individual. Hence, group tests offer an additional source of heterogeneity among the panel members. Overall, 7 tests are proposed. In the limit, the statistics are distributed as standard normal with a left hand side rejection area, except of the variance ratio test, which is right sided. Standardization factors arise from the moments of Brownian motion functionals. The factors depend on the number of regressors and whether or not constants or trends are included in the cointegration relationships. In addition, the Kao and McCoskey (1998) LM test for the null of cointegration is applied. The long run is estimated by efficient methods carried out separately for the panel members. Then, the cointegration residuals are pooled, and the test statistic is asymptotically Gaussian with a right hand side rejection area.

It is important to note that the panel cointegration tests do not provide an estimate of the long run relationship. More or less, the cointegration vector should be common for the panel members, as fundamental economic principles are involved. Also, hypothesis testing is a critical issue. In fact, the asymptotic distribution of the OLS estimator depends on nuisance parameters. In a panel environment, this problem seems to be more serious, as the bias can accumulate with the size of the cross section. To overcome these deficits, efficient methods like fully modified (FMOLS) and dynamic OLS (DOLS) are required. As these techniques control for potential endogeneity of the regressors and serial correlation, asymptotically unbiased estimates of the long run can be obtained. The methods are asymptotically equivalent (Banerjee, 1999). Hence, their relative merits boil down to a comparison in finite samples. In the FMOLS case, nonparametric techniques are used to transform the residuals from the cointegration regression and get rid off nuisance parameters (Phillips, 1995, Pedroni, 2001). In the time series model 


$$
\begin{aligned}
& y_{i t}=\alpha_{i}+\beta_{i} x_{i t}+u_{i t} \\
& x_{i t}=x_{i t-1}+\varepsilon_{i t} \quad, \varpi_{i t}=\left(u_{i t}, \varepsilon_{i t}\right)^{\prime}
\end{aligned}
$$

the asymptotic distribution of the OLS estimator is conditioned to the long run covariance matrix of the joint residual process. The FMOLS estimator for the $i$-th panel member is given by

$$
\hat{\beta}^{*}=\left(X_{i}^{\prime} X_{i}\right)^{-1}\left(X_{i}^{\prime} y_{i}^{*}-T \hat{\delta}\right)
$$

where $y^{*}$ is the transformed endogeneous variable and $d$ a parameter for autocorrelation adjustment. Appropriate correction factors are based on certain submatrices of the joint long run covariance matrix. In the DOLS framework, the long run regression is augmented by lead and lagged differences of the explanatories to control for endogeneous feedback (Saikkonen, 1991). Lead and lagged differences of the dependent variable are included to account for serial correlation (see Stock and Watson, 1993). In particular, the equation

$$
y_{i t}=\alpha_{i}+\beta_{i} x_{i t}+\sum_{j=-p_{1}}^{p_{2}} \delta_{j} \Delta y_{i t-j}+\sum_{j=-q_{1}}^{q_{2}} \lambda_{j} \Delta x_{i t-j}+u_{i t}
$$

is run for the $i$-th panel member, where the appropriate choice of leads and lags is based on data dependent criteria (Westerlund, 2003). Standard errors are computed using the long run variance of the cointegration residuals.

In a panel setting, the cointegration relationship is homogeneous. Heterogeneity is limited to fixed effects, time trends and short run dynamics. The panel FMOLS estimator is the average of the individual parameters (see Pedroni, 2001). According to Mark and Sul (2002) a panel DOLS estimator is obtained using a two step procedure. First, individual dynamic and deterministic components are regressed out separately for the panel members. Then, the residuals are stacked, and a pooled regression is run. As an alternative to these methods, Breitung (2002) has suggested a two step procedure based on a cointegrated VAR model. In the VECM 


$$
\Delta z_{i t}=\alpha_{i} \beta^{\prime} z_{i t-1}+\varepsilon_{i t}
$$

the feedback coefficient $a_{i}$ and the covariance matrix $S_{i}$ of the residuals are allowed to vary across the individuals. As the information matrix of the Gaussian likelihood is asymptotically block diagonal with respect to the short run and cointegration parameters, the long run relation can be uncovered conditional on consistent estimates of the former. Hence, the short run parameters are revealed by individual VECM's, and the restriction that the individuals have a common cointegration vector is temporarily ignored. Then, the variables are transformed according to

$$
\begin{aligned}
z_{i t}^{*} & =\beta^{\prime} z_{i t-1}+\varepsilon_{i t}^{*} \\
z_{i t}^{*} & =\left(\hat{\alpha}_{i}{ }^{\prime} \hat{\Sigma}_{i}{ }^{-1} \hat{\alpha}_{i}\right)^{-1} \hat{\alpha}_{i}{ }^{\prime} \hat{\Sigma}_{i}^{-1} \Delta z_{i t} \\
\varepsilon_{i t}^{*} & =\left(\hat{\alpha}_{i}{ }^{\prime} \hat{\Sigma}_{i}{ }^{-1} \hat{\alpha}_{i}\right)^{-1} \hat{\alpha}_{i}{ }^{\prime} \hat{\Sigma}_{i}{ }^{-1} \varepsilon_{i t}
\end{aligned}
$$

and a pooled regression is run. The long run parameters are asymptotically distributed as standard normal. According to simulation evidence provided by Breitung (2002), his estimator is preferable over FMOLS and DOLS alternatives, as it comes with a smaller finite sample bias.

As a major shortcoming, the panel tests for integration and cointegration presume that the cross sections are independent. However, this requirement is not met in the analysis presented here. For example, medical advancements are correlated across countries. In particular, the presence of cross section cointegration can distort the panel results, see Banerjee, Marcellino and Osbat (2001) and Urbain (2004). In these cases, either the endogeneous variable or specific regressors cointegrate across the panel members. To control for this problem, cointegration tests based on nonstationary common factors are proposed, see Bai (2004), where factors are obtained as principal components. Compa-red to the individual country analysis, the procedure is likely to be more robust, because idiosyncratic (country specific) parts cancel out. 


\section{Data and empirical results}

The health care equation (1) is estimated for a sample of 21 countries using annual series taken from the OECD (2004) health database over the 1975-2001 period. Due to data availability, Italy and Mexico are excluded from the analysis. Variables are in constant prices. As the price index of health expenditures is incomplete for most countries, the private consumption deflator is used instead. GDP has been deflated by the GDP deflator. Real health expenditures and GDP are divided by the total population to obtain per capita terms. Moreover, proxies for the medical progress are employed. Life expectancy and infant mortality are measured in years. All series enter the empirical analysis in logs.

Table 1: Panel unit root test of the variables involved

\begin{tabular}{|l|c|c|c|c|}
\hline A Levels & LLC & Breitung & IPS & Hadri \\
\hline Health care expenditures & 0.91 & 1.00 & 0.54 & $8.37^{*}$ \\
\hline GDP & -1.62 & $-1.71^{*}$ & $-3.33^{*}$ & $7.51^{*}$ \\
\hline Life expectancy & $-3.85^{*}$ & 1.25 & $-3.36^{*}$ & $8.90^{*}$ \\
\hline Infant mortality & $-2.00^{*}$ & 2.96 & $-2.50^{*}$ & $6.20^{*}$ \\
\hline B First differences & LLC & Breitung & IPS & Hadri \\
\hline Health care expenditures & $-12.84^{*}$ & $-5.03^{*}$ & $-13.94^{*}$ & 1.58 \\
\hline GDP & $-10.62^{*}$ & $-7.73^{*}$ & $-11.49^{*}$ & 0.91 \\
\hline Life expectancy & $-26.58^{*}$ & $-18.46^{*}$ & $-24.92^{*}$ & $2.86^{*}$ \\
\hline Infant mortality & $-22.19^{*}$ & $-10.63^{*}$ & $-22.28^{*}$ & 0.81 \\
\hline
\end{tabular}

LLC=Levin, Lin, Chu (2002), IPS=Im, Pesaran, Shin (2003). The other statistics are described in detail in Breitung (2000) and Hadri (2000). The statistics are asymptotically distributed as standard normal with a left hand side rejection area, except of the Hadri test, which is right sided. A * indicates the rejection of the null hypothesis of nonstationarity (LLC, Breitung, IPS) or stationarity (Hadri) at least on the 0.05 level of significance.

The first step is to check for the integration properties of the variables involved. Table 1 shows the results of the panel unit root tests. The level models have been specified with fixed effects and country individual time trends in the data generating process. The time trends amount to fixed effects in the first difference specific ation. More or 
less, a unit root is detected for the level variables, while the first differences appear to be stationary. Due to these results, each variable includes a random walk component.

The panel cointegration tests point to the existence of a long run relationship between health expenditures and GDP per capita, and a measure for the medical progress, see table 2. For example, the null of no cointegration is rejected by most of the Pedroni (1999) tests at the 5 percent level. Given that the long run is estimated using FMOLS, the Kao and McCoskey (1998) test do not reject the null of cointegration.

Table 2: Panel cointegration tests using several indicators of medical progress

\begin{tabular}{|l|c|c|c|c|}
\hline Pedroni (1999) & \multicolumn{2}{|c|}{ Panel Statistics } & \multicolumn{2}{c|}{ Group Statistics } \\
\hline Models including & LE & IM & LE & IM \\
\hline Variance ratio & $3.22^{*}$ & $3.09^{*}$ & & \\
\hline Rho statistic & $-1.74^{*}$ & -1.29 & -0.43 & 0.22 \\
\hline PP statistic & $-3.23^{*}$ & $-2.62^{*}$ & $-3.44^{*}$ & $-2.42^{*}$ \\
\hline ADF statistic & $-3.82^{*}$ & $-3.54^{*}$ & $-4.21^{*}$ & $-3.41^{*}$ \\
\hline $\begin{array}{l}\text { Kao and McCos- } \\
\text { key (1998) }\end{array}$ & \multicolumn{2}{|l|}{ FMOLS residuals } & \multicolumn{2}{|c|}{ DOLS residuals } \\
\hline Models including & LE & IM & LE & IM \\
\hline LM statistic & -1.88 & -1.73 & $2.26^{*}$ & $2.56^{*}$ \\
\hline
\end{tabular}

Models contain real health expenditures, GDP per capita and an alternative indicator of medical progress: Life expectancy (LE) or infant mortality (IM). Statistics are asymptotically distributed as standard normal. The Pedroni statistics are described in detail in Pedroni (1999). The variance ratio test is right-sided, while the other Pedroni tests are left-sided. The LM test from Kao and McCoskey (1998) is right-sided and carried out using either FMOLS or DOLS residuals. A * indicates the rejection of the null hypothesis of no cointegration (Pedroni) or cointegration (Kao and McCoskey) at least on the 0.05 level of significance. 
Table 3: Panel estimation of the cointegration vector Life expectancy as an indicator for medical progress

\begin{tabular}{|l|c|c|}
\hline Method & Income & Medical progress \\
\hline FM (Pedroni, 1999) & $0.96(0.045)$ & $2.98(0.334)$ \\
DOLS (Mark and Sul, 2002) & $1.04(0.094)$ & $2.93(0.599)$ \\
2-Step (Breitung, 2002) & $0.89(0.062)$ & $1.72(0.602)$ \\
\hline
\end{tabular}

Infant mortality as an indicator for medical progress

\begin{tabular}{|l|c|c|}
\hline Method & Income & Medical progress \\
\hline FM (Pedroni, 1999) & $1.01(0.039)$ & $-0.17(0.018)$ \\
DOLS (Mark and Sul, 2002) & $0.85(0.085)$ & $-0.28(0.039)$ \\
2-Step (Breitung, 2002) & $0.67(0.059)$ & $-0.25(0.034)$ \\
\hline
\end{tabular}

Elasticities of real health care expenditures with respect to GDP per capita and elasticities with respect to alternative indicators of medical progress. Standard errors in parantheses.

Estimates of the long run relationship are displayed in table 3. The regressors enter with the correct sign and are highly significant. The elasticity of health expenditures to GDP is not different from 1 in most cases. As an exception, the Breitung (2002) method indicates an elasticity smaller than 1 , provided that medical progress materializes through a decrease of infant mortality. Overall, these results suggest that health care is by no means a luxury. Furthermore, faster medical progress is expected to increase real health expenditures. The evidence is robust for alternative proxies of medical progress.

Finally, a cointegration analysis is performed using common factors. The share of cross section cointegration relationships between the health expenditures (GDP) of two different countries is 14.7 (13.2) percent, where the Johansen procedure is applied. For the other three variables the ratios are 26.8 (life expectancy) and 56.8 (infant mortality). Table 4 gives the results of factor analysis. In particular, principal components are estimated separately for health expenditures, GDP and the alternative indicators of medical progress. For each variable, the first principal component is considered. Then, the cointegration test is performed using standard methods. In carrying out this exercise, the ADF type cointegration test (MacKinnon, 1991) is considered. The cointegrating regression is estimated by the DOLS, and the residuals are checked for stationarity. 
Table 4: Cointegration analysis of common factors.

Several indicators for medical progress

\begin{tabular}{|l|c|c|c|}
\hline & ADF & Income & Medical progress \\
\hline Life expectancy & -4.48 & $0.73(0.140)$ & $0.28(0.136)$ \\
\hline Infant mortality & -4.92 & $0.84(0.055)$ & $-0.16(0.053)$ \\
\hline
\end{tabular}

ADF-test for stationarity of residuals obtained by DOLS methods. According to MacKinnon (1991), the 5 percent critical value is -3.297 . Elasticities of health care expenditures with respect to GDP per capita and elasticities/semielasticities with respect to alternative indicators of medical progress. Standard errors in parantheses.

The cointegration result can be confirmed at the 5 percent level of significance. Moreover, the variables enter the long run relation with the correct sign. However, the elasticities seems to be different from the panel evidence. Especially, the income elasticity is smaller than unity. In addition, the impact of medical progress declines, particularly, if the latter is proxied by life expectancy.

\section{Conclusion}

In this paper the long run relationship between health care expenditures and GDP is examined for a sample of 21 OECD countries using recent developed panel cointegration methods. The analysis accounts for the fact that health expenditures are not only determined by income. The other driving force is medical progress, which can be observed in the evolution of several variables, like life expectancy and infant mortality. A cointegration relationship is established between health care expenditures and GDP and a measure of medical progress. Furthermore, the ncome elasticity is not different from unity in the panel models. Cointegration can even be confirmed when cross section dependencies are taken into account. However, the common factor regressions indicate an income elasticity below unity. Overall, the results imply that health care expenditures are not a luxury good.

\section{References}

Bac, C., Le Pen, Y. (2002) : An international comparison of health care expenditure determinants; Working paper. 
Bai, J. (2004): Estimating cross-section common stochastic trends in nonstationary panel data; Journal of Econometrics 122, 137-183.

Banerjee, A., Marcellino, M., Osbat, C. (2001): Some cautious on the use of panel methods for integrated series of macroeconomic data; IGIER Working paper 170.

Blomqvist, A.G., Carter, R.A. (1997): Is health care really a luxury?; Journal of Health Economics 16, 207-229

Breitung, J. (2000): The local power of some unit root tests for panel data; in Baltagi, B. (ed.): Advances in Econometrics 15. Nonstationary panels, panel cointegration, and dynamic panels, JAI Press, Amsterdam, 161-178.

Breitung, J. (2002): A parametric approach to the estimation of cointegration vectors in panel data, manuscript.

Campbell, J. Y., Perron, P. (1991): Pitfalls and Opportunities: What Macroeconomists should know about Unit Roots, Macroeconomics Annual, National Bureau of Economic Research, 141-201.

Folland, S., Goodman, A.C., Stano, M. (2004): The economics of health and health care; $4^{\text {th }}$ ed., Pearson Prentice Hall, Upper Saddle River, New Jersey.

Gerdtham, U.-G., Löthgren, M. (2000): On stationarity and cointegration of international health expenditure and GDP; Journal of Health Economics 19, 461-475.

Gerdtham, U.-G., Löthgren, M. (2002): New panel results on cointegration of international health expenditure and GDP; Applied Economics 34, 1679-1686.

Hadri, K. (2000): Testing for stationarity in heterogeneous panel data; Econometric Journal 3, 148-161. 
Hansen, P., King, A. (1996): The determinants of health care expenditure: A cointegration approach; Journal of Health Economics 15, 127-137.

Hitiris, T., Posnett, J. (1992): The determinants and effects of health expenditure in developed countries; Journal of Health Economics 11, 173-181.

Im, K.S., Pesaran, M.H., Shin, Y. (2003): Testing for unit roots in heterogeneous panels; Journal of Econometrics 115, 53-74.

Jewell, T., Lee, J., Tieslau, M., Strazicich, M.C. (2003): Stationarity, health expenditures and GDP. Evidence from panel unit root tests with heterogeneous structural breaks; Journal of Health Economics 22, 313-323.

Johansen, S. (1991): Estimation and hypothesis testing of cointegration vectors in gaussian vector autoregressive models; Econometrica $59,1551-1580$.

Kao, Chiwa, McCoskey, Suzanne (1998): A residualbased test of the null of cointegration in panel data; Econometric Reviews 17, 5784.

Levin, A., Lin, C.F., Chu, C. (2002): Unit root tests in panel data: Asymptotic and finite sample properties; Journal of Econometrics $108,1-24$.

Lichtenberg, F.R. (2004): Sources of U.S. longevity increase, 19602001; Quarterly Review of Economics and Finance 44, 369-389.

MacKinnon, J.G. (1991): Critical values for cointegration tests, in Engle, R.F., Granger, C.W.J. (eds): Long-run economic relationships; Readings in Cointegration, Oxford University Press, Oxford.

MacKinnon, J.G., Haug, A.A., Michelis, L. (1999): Numerical distribution functions of likelihood ratio tests for cointegration; Journal of Applied Econometrics 14, 563-577. 
Mark, Nelson C., Sul, Donggyu (2002): Cointegration vector estimation by Panel DOLS and long-run money demand; manuscript.

McCoskey, S.K., Selden, T.M. (1998): Health care ecpenditures and GDP: Panel data unit root test results; Journal of Health Economics 17, 369-376.

Newey, Whitney K., West, Kenneth D. (1994): Automatic lag sele ction in covariance matrix estimation, Review of Economic Studies 61, 631-653.

Newhouse, J.P. (1977): Medical care expenditures: A cross-national survey; Journal of Human Resources 12, 115-125.

OECD (1985): Measuring health care 1960-1983. Expenditure, costs and performance; Paris.

OECD (2004): Health database, Paris.

Okunade, A. (2004): Concepts, measures and models of technology and technical progress in medical care and health economics; Quarterly Review of Economics and Finance 44, 363-368.

Okunade, A., Karakus, M.C. (2001): Unit root and cointegration tests: Time series versus panel estimates for international health expenditure models; Applied Economics 33, 1131-1137.

Pedroni, Peter (1999): Critical values for cointegration tests in heterogeneous panels with multiple regressors; Oxford Bulletin of Economics and Statistics 61, Special Issue, 653-670.

Pedroni, Peter (2001): Purchasing power parity tests in cointegrated panels; Review of Economics and Statistics 83, 727-731.

Phillips, Peter C.B. (1995): Fully modified least squares and vector autoregression; Econometrica 63, 1023-1078. 
Roberts, J. (1999): Sensitivity of elasticity estimates for OECD health care spending: analysis of dynamic heterogenous data field; Health Economics 8, 459-472.

Saikkonen, Pentti (1991): Asymptotically efficient estimation of cointegration regression; Econometric Theory 7, 1-21.

Stock, James H., Watson, Mark W. (1993): A simple estimator of cointegration vectors in higher order integrated systems; Econometrica $61,783-820$.

Urbain, J.-P. (2004) : Spurious regression in nonstationary panels with cross-member cointegration, manuscript.

Westerlund, Joakim (2003): Feasible estimation in cointegrated panels; Discussion paper, Department of Economics, University of Lund.

Journal IJAEQS published by EAAEDS: http://www.usc.es/economet/eaa.htm 